\title{
Efeitos de Contingências de Punição Sobre os Desempenhos Verbal e não Verbal ${ }^{1}$
}

\author{
Elisa Tavares Sanabio ${ }^{2}$ \\ Universidade Católica de Goiás \\ Josele Abreu-Rodrigues \\ Universidade de Brasília
}

\begin{abstract}
RESUMO: O presente estudo investigou a influência de contingências de punição sobre os desempenhos verbal (resposta de relato) e não verbal (resposta de escolha). Estudantes universitários foram expostos a uma tarefa de escolha de acordo com o modelo. Após a resposta de escolha, a pergunta "Você acertou?" era apresentada e o participante deveria emitir a resposta de relato, indicando uma dentre duas alternativas, "SIM" e "NÃO". No Experimento 1, o feedback "Incorreto. Você perdeu 1 ponto" foi programado para a resposta de relato e, no Experimento 2, o feedback foi contingente à resposta de escolha. No Experimento 1, o feedback exerceu funções punitivas sobre a resposta de relato e, na maioria das condições, não afetou a resposta de escolha. No Experimento 2, o feedback não exerceu controle sobre a resposta de escolha, embora tenha influenciado as respostas de relato. Esses resultados sugerem que os desempenhos verbal e não verbal são funcionalmente independentes. O presente estudo evidencia o caráter operante do relato e, ao identificar possíveis variáveis de controle desse comportamento, contribui para uma maior fidedignidade dos dados obtidos por meio de auto-relatos.
\end{abstract}

Palavras-chave: punição; auto-relato; controle verbal.

\section{The Effects of Punitive Contingencies Upon Verbal and Nonverbal Performances}

\begin{abstract}
This study examined the influence of punishment contingencies on verbal (report responses) and nonverbal (matching responses) performances. College students were exposed to a matching-to-sample task. After a matching response was made, the question "Did you score?" was presented and the subject had to make a report indicating one of two alternatives, "YES" or "NO". In Experiment 1, the feedback "Incorrect. You lost 1 point" was scheduled to report responses whereas, in Experiment 2, the same feedback was contingent on matching responses. In Experiment 1, the feedback had punitive effects on report responses and, in most conditions, did not affect matching responses. In Experiment 2, the feedback did not exerted control upon matching responses, but it influenced report responses. These results suggest that verbal and nonverbal performances are functionally independent. The present study provide evidence for the operant nature of self-reports and, in identifying possible control variables of such behavior, it contributes to a greater reliability of self-report data.
\end{abstract}

Key words: punishment; self-reports; verbal control.

Os indivíduos não somente respondem a estímulos verbais fornecidos por outras pessoas (Kaufman, Baron \& Kopp, 1966; Galizio, 1979; LeFrancois, Chase \& Joyce, 1988; Danforth, Chase, Dolan \& Joyce, 1990; Simonassi, Oliveira \& Gosch, 1997; Otto, Torgrud \& Holborn, 1999; Raia, Shillingford, Miller Jr. \& Baier, 2000), mas também respondem aos estímulos verbais gerados por eles mesmos (Catania, Matthews \& Shimoff, 1982; Torgrud \& Holborn, 1990; Rosenfarb, Newland, Brannon \& Howey, 1992; Ono, 1994; Dixon \& Hayes, 1998). Nesse último caso, os estímulos verbais consistem, muitas vezes, em descrições de relações entre o comportamento do próprio indivíduo, seja ele público

1 O Experimento 1 derivou da dissertação de mestrado da primeira autora, defendida no Instituto de Psicologia, UnB, em fevereiro de 2000, sob orientação da segunda autora. Agradecemos a Weber Martins pelo desenvolvimento do software.

2 Endereço: Rua T-65, $\mathrm{n}^{\circ}$ 160, apto. 301. Setor Bela Vista. 74823-370 Goiânia, Goiás. E-mail: esanabio@terra.com.br. ou privado, e seus eventos antecedentes e conseqüentes, sendo tais descrições denominadas de auto-relatos.

Os auto-relatos exercem papéis diferenciados na pesquisa em Psicologia. Em alguns estudos, os auto-relatos funcionam como um instrumento para acessar eventos privados, sendo estes eventos o foco primário de interesse do pesquisador. A relevância dos auto-relatos nesses estudos apóia-se no pressuposto de que os mesmos permitiriam o acesso às regras formuladas pelos próprios indivíduos, denominadas de auto-regras (Critchfield, Tucker \& Vuchinich, 1998; Perone, 1988). Esse pressuposto está presente em procedimentos experimentais em que os sujeitos são expostos a um determinado esquema de reforçamento e, posteriormente, questionados acerca de seus desempenhos não verbais, conforme exemplificado pelo estudo de Bentall, Lowe e Beasty (1985). Com o objetivo de investigar os efeitos do comportamento verbal sobre o comportamento não verbal, crianças com idades variando de 6 meses a 9 anos foram expostas a esquemas de intervalo fixo (FI) que variavam de $10 \mathrm{~s}$ a $70 \mathrm{~s}$. Para as crianças pré-verbais, os esquemas FI geraram desempe- 
nhos semelhantes àqueles obtidos com sujeitos não humanos, ou seja, pausa pós-reforço seguida por um aumento gradual na taxa de respostas. As crianças verbais, por outro lado, responderam em taxas baixas ou taxas altas, desempenhos comumente observados com humanos adultos. Além disso, essas crianças apresentaram correspondência entre o relato do que deveria ser feito para produzir os reforços e o desempenho nos esquemas FI. A partir desses dados, os autores não somente assumiram que os relatos obtidos refletiram as auto-regras formuladas durante a tarefa experimental, como também afirmaram que, uma vez que sujeitos humanos aprendem a descrever as contingências, isto é, a formular regras, seus comportamentos não verbais deixam de ser diretamente controlados pelas contingências de reforçamento e passam a ser função dessas auto-regras.

Problemas relativos a essa abordagem dos auto-relatos foram apontados por Shimoff (1986). O primeiro deles refere-se à afirmação de que o desempenho não verbal durante o procedimento experimental evoca, inevitavelmente, processos verbais. Entretanto, é possível encontrar comportamentos não verbais que ocorrem sem a participação de qualquer comportamento verbal. O segundo problema está relacionado à premissa de que há correspondência entre os auto-relatos e as auto-regras formuladas durante a sessão experimental ou, alternativamente, que eventos privados (nesse caso, as auto-regras) estariam exercendo controle discriminativo sobre os auto-relatos. Entretanto, uma vez que os eventos privados são inacessíveis à comunidade verbal, o reforçamento diferencial dos relatos de tais eventos é bastante dificultado e, conseqüentemente, sua função discriminativa fica comprometida. $\mathrm{O}$ terceiro e último problema está relacionado à noção de causalidade encontrada nesse tipo de estudo: os processos verbais que ocorrem durante a sessão são considerados determinantes do comportamento não verbal observado. Sob uma perspectiva analítico-comportamental, toda e qualquer causa deve ser buscada no ambiente, o que implica em dizer que qualquer relação comportamento-comportamento é estabelecida por contingências ambientais (Hayes, 1986).

Em outros estudos, o auto-relato deixa de ser um instrumento para acessar eventos privados e passa a ser investigado enquanto variável dependente, de modo que o objetivo central do pesquisador consiste em identificar suas fontes ambientais de controle. Exemplos desse segundo tipo de abordagem dos auto-relatos podem ser encontrados nos experimentos realizados por Critchfield e cols. (Critchfield \& Perone, 1990, 1993; Critchfield, 1993). Nesses estudos, estudantes universitários foram expostos a uma tarefa de escolha de acordo com o modelo, onde estímulos-modelo eram apresentados e, após um atraso de $1 \mathrm{~s}$, estímulos de comparação apareciam na tela. A resposta de escolha só era reforçada se o sujeito escolhesse o estímulo de comparação idêntico a um dos estímulos-modelo e caso o fizesse dentro de um limite de tempo específico. Após a escolha, a pergunta "Você acertou?" aparecia na tela e o sujeito deveria emitir auto-relatos escolhendo uma de duas opções de resposta, "SIM" ou "NÃO". Vários fatores demonstraram exercer in- fluência sobre os auto-relatos: o limite de tempo para a resposta de escolha (Critchfield \& Perone, 1990), o número de estímulos-modelo (Critchfield \& Perone, 1993) e o número de estímulos de comparação (Critchfield, 1993).

Em um estudo adicional, Critchfield (1996) observou que os relatos "NÃO" (relatos de erro ou insucesso) apresentaram tempos de reação mais longos que aqueles dos relatos "SIM" (relatos de acerto ou sucesso). Ou seja, os sujeitos demoravam mais tempo para dizer que haviam errado do que para dizer que haviam acertado. Esses resultados foram atribuídos a uma possível história de punição. Ou seja, considerando que a punição diminui a prontidão do responder (Skinner, 1957), o autor sugeriu que o tempo de reação mais longo dos relatos "NÃO" foram decorrentes de contingências passadas de punição estabelecidas pela comunidade verbal para os relatos de insucesso.

Os efeitos de contingências punitivas sobre o desempenho verbal foram investigados no presente estudo por meio de um procedimento de escolha de acordo com o modelo semelhante àquele dos estudos de Critchfield e cols. Para tanto, no Experimento 1, conseqüências punitivas foram programadas para os relatos "SIM" " "NÃO". O estudo em questão também verificou a influência de contingências punitivas sobre o grau de acurácia do desempenho não verbal. Desse modo, no Experimento 2, a punição foi implementada para as escolhas CORRETAS e INCORRETAS.

\section{Experimento 1}

Critchfield (1996) sugeriu que contingências de punição estabelecidas pela comunidade verbal podem ser responsáveis por possíveis diferenças entre relatos de insucesso e relatos de sucesso. Dessa forma, o Experimento 1 teve como objetivos: (a) estabelecer experimentalmente contingências de punição para as respostas verbais e (b) observar os efeitos de tais contingências sobre as respostas não verbais.

\section{Método}

\section{Participantes}

Quatro alunos dos cursos de graduação em Administração, Física e Ciências da Computação da Universidade de Brasília (UnB), todos do sexo masculino e com idade variando de 18 a 23 anos. Os participantes ganharam 0,5 ponto (o equivalente a $5 \%$ da nota máxima), em disciplinas do Departamento de Processos Psicológicos Básicos, por cada hora empregada no experimento e participaram do sorteio de uma quantia de $\mathrm{R} \$ 50,00$.

\section{Ambiente / Equipamento / Material}

O experimento foi conduzido em uma sala $(2 \times 2 \mathrm{~m})$ com isolamento acústico parcial, contendo uma mesa, um microcomputador, uma impressora e uma cadeira. $\mathrm{O}$ controle das contingências experimentais e o registro dos dados foram realizados por meio de um programa desenvolvido em lin- 
guagem Visual Basic com chamadas de rotina em Assembler. Foram utilizadas fichas para o sorteio, confeccionadas em papel cartolina.

\section{Procedimento}

Todos os participantes foram expostos a duas etapas: uma etapa preliminar e uma etapa experimental.

Etapa Preliminar. Esta primeira etapa teve como objetivo familiarizar os participantes com o procedimento de escolha de acordo com o modelo. Os estímulos utilizados para o modelo e para as comparações consistiram em letras gregas.

Três estímulos-modelo eram apresentados na tela do monitor durante $3 \mathrm{~s}$. Ao final desse período, os três estímulos-modelo eram retirados e iniciava-se um intervalo de $2 \mathrm{~s}$, durante o qual a tela permanecia sem estímulos. Após esse intervalo, dois estímulos de comparação eram apresentados. O participante deveria, então, emitir uma resposta de escolha, a qual consistia em clicar com o mouse em um dos estímulos de comparação. Se a escolha fosse correta, isto é, se o estímulo de comparação escolhido fosse idêntico a um dos estímulos-modelo, ofeedback "Escolha correta. Você ganhou 1 ponto" aparecia na tela; se a escolha fosse incorreta, isto é, se o participante escolhesse o estímulo de comparação diferente de cada um dos estímulos modelo, o feedback "Escolha incorreta. Você não ganhou 1 ponto" era apresentado. Após a apresentação do feedback, a mensagem "Pressione a barra de espaço para iniciar uma nova tentativa" aparecia na tela. $\mathrm{O}$ total de pontos ganhos era apresentado em um contador que se situava no canto superior esquerdo do monitor e que permanecia na tela, durante a apresentação dos estímulos-modelo e dos estímulos de comparação, até a finalização da etapa preliminar.

Quando o critério para mudança de condição era alcançado, isto é, o participante apresentava $70 \%$ de respostas corretas em um mínimo de 10 tentativas, iniciava-se a etapa experimental. Caso o critério não fosse alcançado, a sessão se encerrava com 30 tentativas e o participante era dispensado do experimento.

A seguinte instrução era apresentada aos participantes antes do início dessa etapa:

Este é um experimento sobre aprendizagem.

No monitor à sua frente, aparecerão 3 figuras-modelo na parte superior da tela. Em seguida, aparecerão 2 figuras de comparação na parte inferior da tela. Sua tarefa consiste em escolher a figura de comparação idêntica a uma das figuras-modelo. Para tanto, você deve clicar com o mouse na figura de comparação escolhida.

Após sua resposta de escolha, aparecerá uma mensagem indicando (a) se sua escolha foi correta ou incorreta, (b) se você ganhou 1 ponto ou não e (c) o total de pontos ganhos até o momento, que será apresentado em um contador situado no canto superior esquerdo da tela durante toda a sessão. Ao término da sessão, cada 5 pontos ganhos serão trocados por uma ficha que lhe permitirá participar de um sorteio programado para o final do experimento. Quanto mais pontos você fizer, mais fichas receberá e, conseqüentemente, mais chances terá de ganhar o sorteio.

Clique OK quando estiver pronto para começar.

Etapa Experimental. Os estímulos utilizados durante esta etapa consistiram em uma matriz $4 \times 3$, cujas células eram coloridas de azul e amarelo, formando várias figuras (para um exemplo dos estímulos, ver Critchfield, 1996).

No início de cada tentativa, três estímulos-modelo apareciam na tela por um período de $3 \mathrm{~s}$. Após a apresentação dos estímulos-modelo, iniciava-se um intervalo de $2 \mathrm{~s}$, durante o qual a tela permanecia sem estímulos. Ao final deste intervalo, dois estímulos de comparação eram apresentados e o participante deveria emitir uma resposta de escolha, que consistia em clicar com o mouse em um desses estímulos. Respostas de escolha corretas ocorriam quando o estímulo de comparação idêntico a um dos estímulos-modelo era escolhido; caso este estímulo não fosse escolhido, a resposta de escolha era considerada incorreta. Entretanto, o participante não recebia nenhum feedback informando se sua escolha estava correta ou incorreta. Em seguida, o participante deveria emitir uma resposta de relato, ou seja, uma pergunta ("Você acertou?") aparecia na tela e, para respondê-la, o participante deveria indicar uma entre duas alternativas de respostas: "SIM" e "NÃO".

Essa etapa compreendia quatro condições experimentais. Cada condição, em vigor durante uma sessão, era composta por 60 tentativas. Em todas as condições, a apresentação do feedback "Incorreto. Você perdeu 1 ponto" foi programada para as respostas de relato, sendo que as quatro condições experimentais se diferenciavam apenas em relação ao tipo de relato ("SIM" e "NÃO") ao qual o feedback era contingente. As respostas de escolha não produziam o feedback.

Na condição de Linha de Base (LB), o feedback nunca era apresentado.

Na condição SIM (S), os relatos "SIM" produziam o feedback $100 \%$ das vezes em que ocorriam, enquanto os relatos "NÃO" nunca geravam o feedback. Assim, quando o participante relatava que tinha escolhido corretamente, o feedback era sempre apresentado e quando o participante relatava que tinha errado, nenhum feedback era fornecido.

$\mathrm{Na}$ condição SIM/NÃO (S/N), os relatos "SIM" produziam o feedback $50 \%$ das vezes, assim como os relatos "NÃO". Quatro tipos de relações escolha-relato eram possíveis: duas caracterizadas pela correspondência entre escolha e relato (escolha correta-relato "SIM" e escolha incorreta-relato "NÃO") e duas que indicavam a ausência de correspondência entre essas respostas (escolha correta-relato "NÃO" e escolha incorreta-relato "SIM"). Considerando que, nesta condição, metade dos relatos "NÃO" (e metade dos relatos "SIM") receberia feedback, era possível consequenciar sempre a relação escolha incorreta-relato "NÃO" (correspondência) e nunca consequenciar a relação escolha correta-relato "NÃO" (não correspondência) e, mesmo assim, seguir o critério de $50 \%$ de feedback para os relatos "NÃO" (o mesmo poderia acontecer com o relato "SIM"). Dessa forma, para evitar consequenciar apenas a correspondência 
ou apenas a ausência de correspondência entre a resposta de escolha e a resposta de relato, a apresentação do feedback foi balanceada entre as quatro relações escolha-relato, de modo que cada relação recebeu feedback em apenas $50 \%$ das vezes.

$\mathrm{Na}$ condição NÃO $(\mathrm{N})$, os relatos "NÃO" recebiam feedback $100 \%$ das vezes em que ocorriam e os relatos "SIM" nunca eram consequenciados. Ou seja, quando o participante relatava que havia errado, ofeedback era sempre apresentado e quando relatava que havia acertado, nenhum feedback era produzido.

Em seguida, os participantes retornavam à condição de Linha de Base (LB).

A ordem das condições foi alterada entre os participantes. Dois participantes foram expostos às condições experimentais na seqüência $\mathrm{LB}-\mathrm{S}-\mathrm{S} / \mathrm{N}-\mathrm{N}-\mathrm{LB}$ (seqüência SIM), enquanto os outros dois passaram pela seqüência $\mathrm{LB}$ $-\mathrm{N}-\mathrm{S} / \mathrm{N}-\mathrm{S}-\mathrm{LB}$ (seqüência NÃO).

Respostas corretas de escolha resultavam no registro e acréscimo de um ponto ao total de pontos, enquanto respostas incorretas de escolha produziam a diminuição de um ponto do total de pontos da sessão. Os pontos perdidos após os relatos eram subtraídos do total de pontos registrados para as respostas de escolha. Caso, ao final da sessão, o total de pontos estivesse negativo, o participante não recebia fichas para participar do sorteio. Nenhum contador era apresentado na tela e, assim, os participantes não recebiam qualquer informação sobre o total de pontos ao longo da sessão.

A seguinte instrução foi apresentada aos participantes antes da etapa experimental:

Este é um experimento sobre aprendizagem.

No monitor à sua frente, aparecerão 3 figuras-modelo na parte superior da tela. Em seguida, aparecerão 2 figuras de comparação na parte inferior da tela. Sua tarefa consiste em escolher a figura de comparação idêntica a uma das figuras-modelo. Para tanto, você deve clicar com o mouse na figura de comparação escolhida.

Se sua escolha for correta, o computador irá acrescentar 1 ponto ao contador; se sua escolha for incorreta, o computador irá subtrair 1 ponto do contador. Entretanto, você não receberá nenhuma mensagem indicando se sua escolha foi correta ou incorreta, nem se você ganhou ou perdeu 1 ponto. Além disso, o contador com o número total de pontos não será apresentado na tela.

Após cada escolha da figura de comparação, o computador lhe fará uma pergunta e apresentará algumas alternativas de resposta. Para responder, você deverá clicar com o mouse em uma das alternativas. Dependendo da sua resposta, você receberá uma mensagem indicando que você perdeu 1 ponto. Os pontos perdidos pela resposta à pergunta serão subtraídos dos pontos ganhos pela escolha da figura de comparação. Cada 5 pontos ganhos serão trocados por uma ficha que lhe permitirá participar do sorteio programado para o final do experimento.

Se, ao final da sessão, o contador com o total de pontos estiver negativo, você não receberá fichas para o sorteio. Quanto mais pontos você fizer, mais fichas receberá e, conseqüentemente, terá mais chances de ganhar o sorteio.

Clique OK quando estiver pronto para começar “.

\section{Resultados e Discussão}

Dois tipos específicos de resposta eram possíveis, respostas de escolha e respostas de relato. Uma vez que o feedback foi contingente a resposta de relato, a mesma será analisada primeiramente.

\section{Relatos "SIM" e "NÃO"}

A Figura 1 mostra a porcentagem dos relatos precisos e imprecisos por oportunidade, em cada condição, para os participantes da seqüência SIM. Essa porcentagem foi obtida, para cada participante, dividindo-se o número de ocorrências de cada um dos relatos pelo número de oportunida-
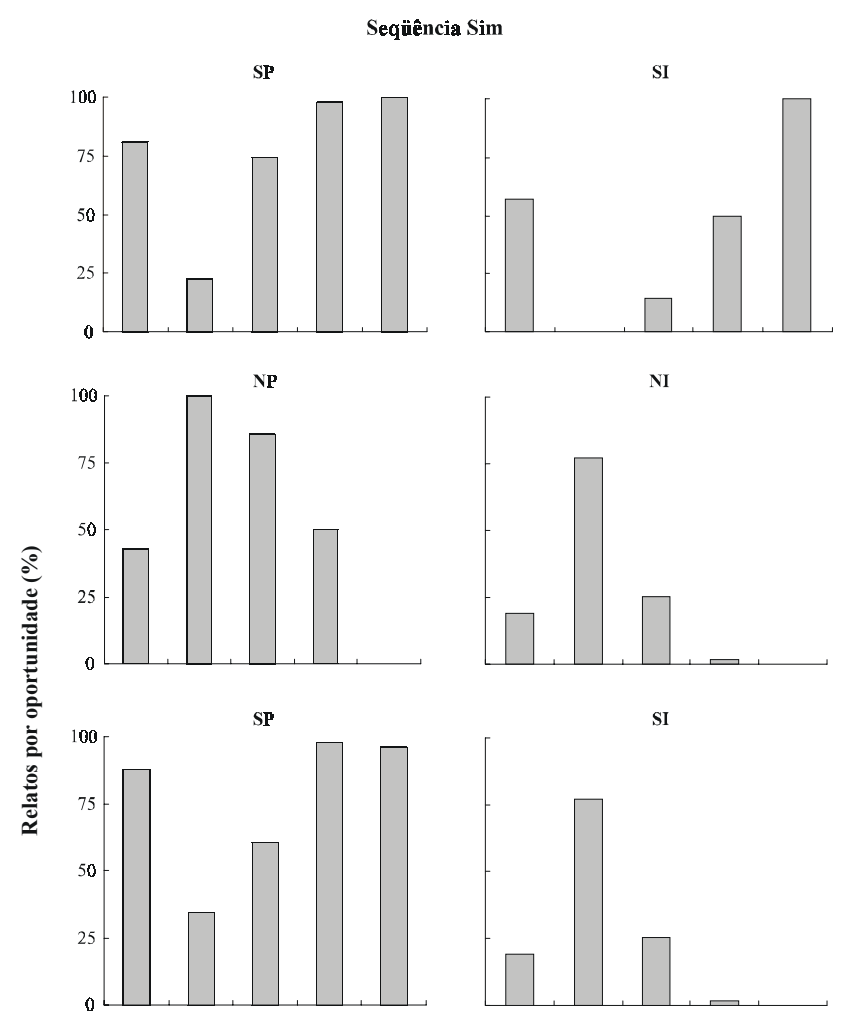

SI

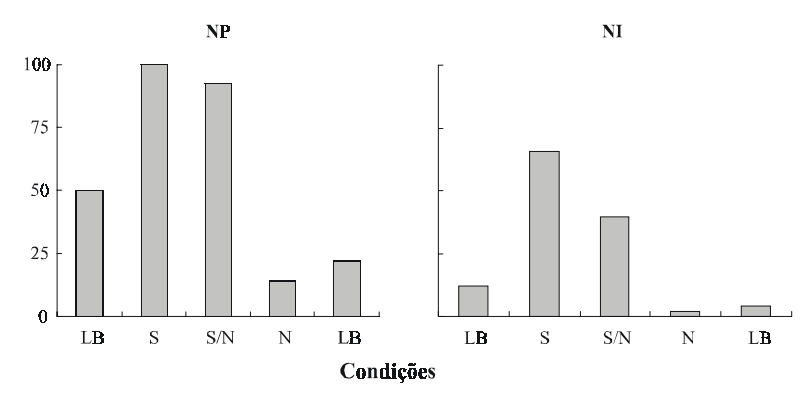

Figura 1. Porcentagem de relatos "SIM" precisos (SP) e imprecisos (SI) e "NÃO" precisos (NP) e imprecisos (NI) por oportunidade para os participantes da seqüência SIM, em cada condição experimental. 
des para a sua emissão: escolhas corretas eram oportunidades para relatos "SIM" precisos (SP) e "NÃO" imprecisos (NI), sendo as escolhas incorretas oportunidades para relatos "NÃO" precisos (NP) e "SIM" imprecisos (SI). Dessa forma, os relatos precisos representam a correspondência entre fazer e dizer (relato "SIM" após escolha correta e relato "NÃO" após escolha incorreta), sendo os relatos imprecisos caracterizados pela ausência dessa correspondência (relato "SIM" após escolha incorreta e relato "NÃO" após escolha correta). Para os dois participantes, os relatos "SIM" são apresentados acima dos relatos "NÃO", enquanto os relatos precisos são apresentados à esquerda e os imprecisos, à direita.

Uma primeira análise pode ser feita comparando as porcentagens dos relatos "SIM" e "NÃO". É possível observar que, na primeira condição LB, a porcentagem dos relatos "SIM" foi maior que a dos relatos "NÃO". Nas condições S e N, a porcentagem de relatos com feedback (relatos "SIM" para a condição $\mathrm{S}$ e relatos "NÃO" para a condição N) foi menor que a porcentagem dos relatos sem feedback (relatos "NÃO" para a condição S e relatos "SIM" para a condição $\mathrm{N})$. Na condição $\mathrm{S} / \mathrm{N}$, observou-se que os relatos "SIM" foram menos freqüentes que os relatos "NÃO", enquanto que na última condição (LB), o inverso ocorreu. Além disso, comparando as duas condições de LB, é possível observar que os relatos "SIM" foram emitidos em uma freqüência maior na segunda LB; em relação aos relatos "NÃO", estes foram menos freqüentes na segunda LB.

A Figura 2 apresenta uma análise similar àquela da Figura 1 para os participantes da seqüência NÃO.

A comparação das porcentagens dos relatos "SIM" e "NÃO", na primeira condição LB e nas condições S e N, indica resultados semelhantes aos da Figura 1: a porcentagem dos relatos "SIM" foi similar (participante VT) ou superior (participante $\mathrm{AL}$ ) a dos relatos "NÃO" na primeira condição LB, enquanto que nas condições $\mathrm{S}$ e $\mathrm{N}$, a porcentagem dos relatos com feedback foi menor que a porcentagem dos relatos sem feedback. Nas condições $\mathrm{S} / \mathrm{N}$ e na última condição LB, entretanto, foram observados efeitos da ordem de exposição às condições. Na condição $\mathrm{S} / \mathrm{N}$, a freqüência dos relatos "SIM" foi similar (participante VT) ou superior (participante AL) a dos relatos "NÃO". Na última condição LB, foi observado uma diminuição dos relatos "SIM" e um aumento dos relatos "NÃO", com relação à primeira condição LB.

\section{Relatos precisos e imprecisos}

Uma vez que os relatos com feedback foram menos freqüentes que os relatos sem feedback, é possível sugerir que o feedback exerceu funções punitivas. Sendo assim, os relatos serão referidos, daqui por diante, como relatos punidos (aqueles que recebiam feedback) ou não punidos (aqueles que não recebiam feedback). Considerando que tanto os relatos punidos quanto os não punidos apresentaram alterações em função da contingência de punição programada, independente do tipo de relato ("SIM" ou "NÃO"), a ques-

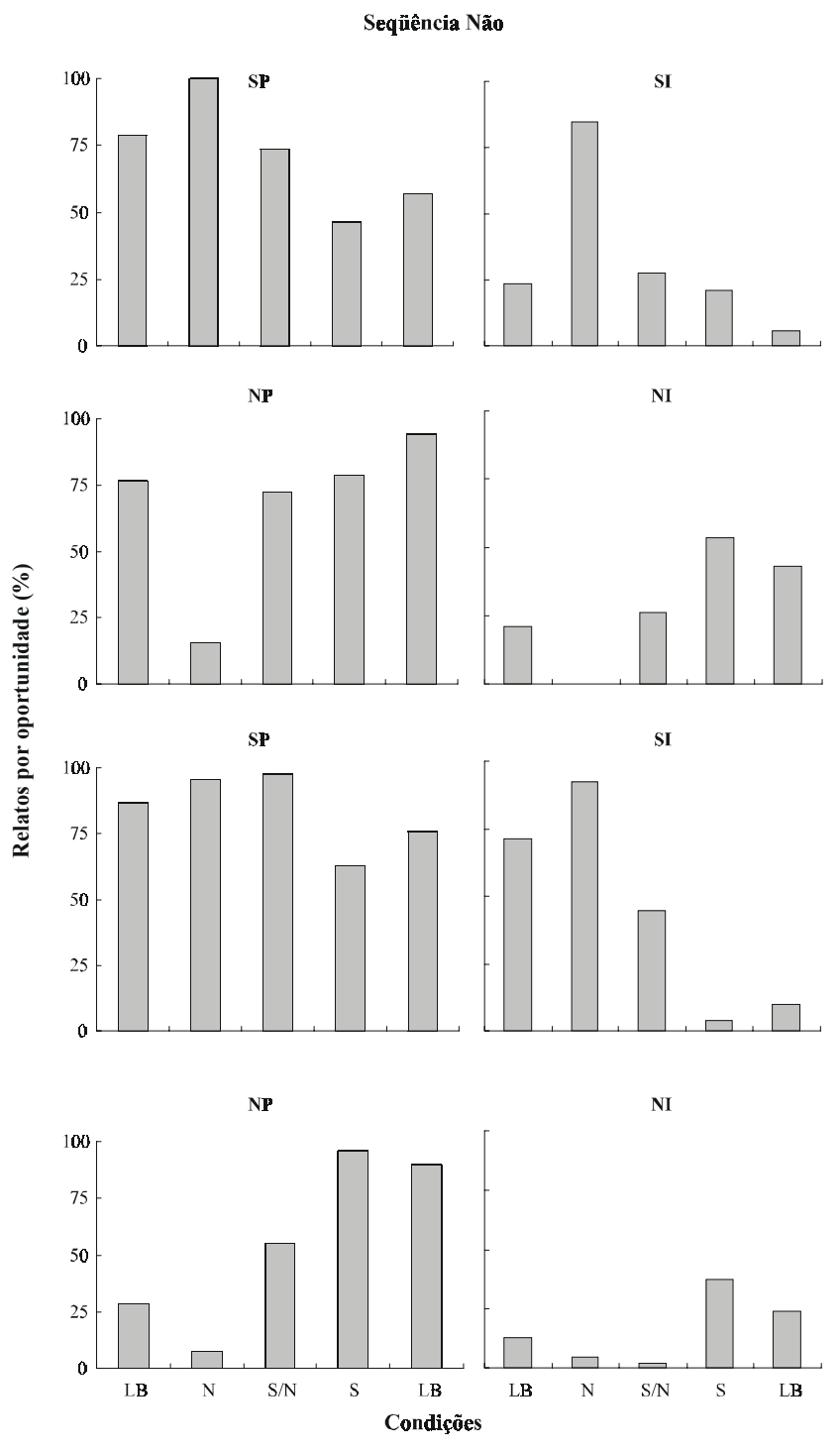

Figura 2. Porcentagem de relatos "SIM" precisos (SP) e imprecisos (SI) e "NÃO" precisos (NP) e imprecisos (NI) por oportunidade para os participantes da seqüência NÃO, em cada condição experimental.

tão que se segue é se tal contingência também gerou efeitos sistemáticos no nível de precisão desses relatos. A comparação dos relatos precisos e imprecisos, apresentada nas Figuras $1 \mathrm{e} 2$, mostra que os relatos precisos foram mais freqüentes que os relatos imprecisos para os participantes das seqüências SIM e NÃO, sendo tal resultado observado em todas as condições, tanto para os relatos "SIM" quanto para os relatos "NÃO".

\section{Respostas de escolha}

A Figura 3 apresenta a porcentagem de escolhas corretas para os participantes da seqüência SIM e os participantes da seqüência NÃO, em cada condição. A porcentagem de escolhas corretas de cada participante foi obtida dividindo-se o número de escolhas corretas pelo número total de respostas de escolha (corretas e incorretas) em cada condição. Os 
dados dos participantes da seqüência SIM são apresentados na parte superior e dos participantes da seqüência NÃO, na parte inferior.

Para os participantes da seqüência SIM, as porcentagens de escolhas corretas foram semelhantes nas duas condições de LB e na condição N (aproximadamente 90\%), tendo sido observado uma diminuição nessa porcentagem nas condições S e S/N (aproximadamente 60\%). Para os participantes da seqüência NÃO, a porcentagem de escolhas corretas se manteve semelhante em todas as condições experimentais (aproximadamente 75\%), sendo que uma pequena diminuição foi observada na condição S para o participante AL (aproximadamente $60 \%$ ). A análise de variância indicou diferenças estatisticamente significativas entre as condições dos participantes da seqüência $\operatorname{SIM}(\mathrm{F}[4,5]=19,0493, p=$ 0,0031). A aplicação do teste Tukey e do teste Duncan indi-

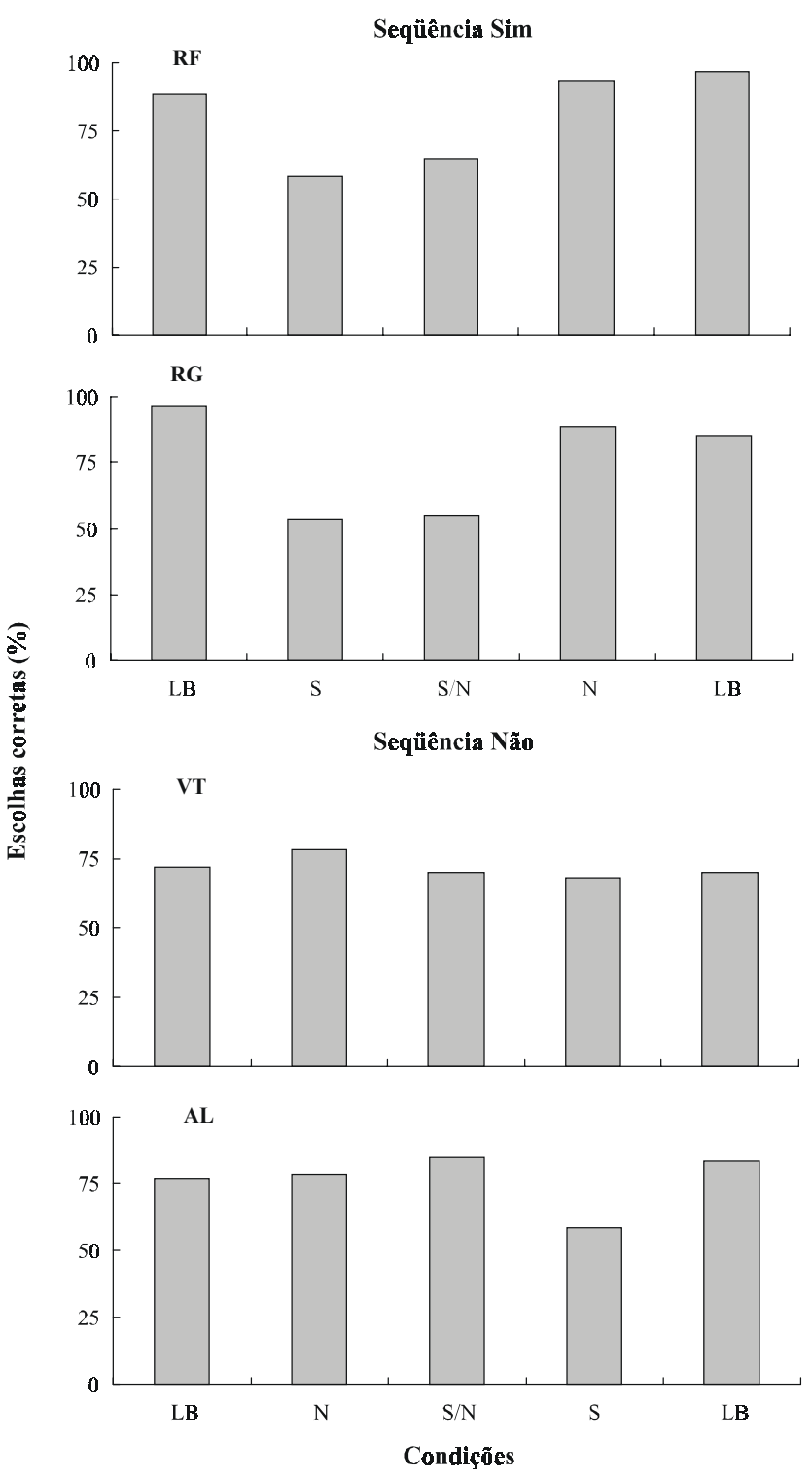

Figura 3. Porcentagem de escolhas corretas para os participantes da seqüência SIM (RF e RG) e para os participantes da seqüência NÃO (VT e AL), em cada condição experimental. cou que tais diferenças ocorreram entre as condições com feedback para os relatos "SIM" ( $\mathrm{S}$ e $\mathrm{S} / \mathrm{N})$ e as demais condições. Para os participantes da seqüência NÃO, a análise de variância não indicou diferenças estatisticamente significativas.

Os dados acima apresentados podem assim ser resumidos. Considerando apenas os relatos "SIM" e "NÃO", as Figuras 1 e 2 mostram um efeito sistemático da contingência de punição programada para esses relatos: nas condições $\mathrm{S}$ e $\mathrm{N}$, a porcentagem do relato que recebia feedback foi menor que aquela do relato sem feedback. Ou seja, quando o participante emitia a resposta de escolha correta, relatava que havia acertado e ocorria punição para esse relato, esse participante passava a relatar que havia errado, a despeito da acurácia de suas escolhas. Da mesma forma, quando o participante emitia uma resposta de escolha incorreta e havia punição para o relato de erro, os relatos de acerto passavam a ser emitidos em uma freqüência elevada, mesmo diante de escolhas incorretas. Esses resultados indicam que ofeedback exerceu funções punitivas ou, alternativamente, que o relato foi sensível às suas conseqüências, corroborando a sugestão de Critchfield (1996).

A sensibilidade do comportamento verbal a contingências de punição também foi observada por Smith, Michael e Sundberg (1996). Nesse estudo, duas crianças de 11 e 14 meses foram expostas a três condições experimentais, sendo cada condição dividida em três fases. Na primeira fase (linha de base), todas as verbalizações eram registradas e, então, alguns fonemas emitidos pelas crianças eram definidos como a resposta alvo. Na fase seguinte (pareamento), o próprio experimentador emitia a resposta alvo para a criança e, logo em seguida, apresentava estímulos reforçadores, neutros ou punitivos, dependendo da condição. A última fase (pós-pareamento) era um retorno à linha de base. Na condição onde os estímulos punitivos eram utilizados, cada fonema emitido pelo experimentador era seguido pela expressão "Má menina" durante a fase de pareamento. Os resultados da fase de pós-pareamento dessa condição demonstraram que, inicialmente, todos os fonemas registrados na linha de base tiveram suas freqüências reduzidas e que, posteriormente, apenas os fonemas anteriormente emparelhados com "Má menina" continuaram apresentando uma freqüência reduzida.

Outro aspecto importante refere-se à condição $\mathrm{S} / \mathrm{N}$, na qual as porcentagens dos relatos dependeram da condição anterior. Quando relatos de acerto e de erro eram similarmente punidos, o participante tendia a relatar erro caso seus relatos de acerto tivessem sido anteriormente punidos ou a relatar acerto diante de uma experiência prévia com punição para relatos de erro. Os efeitos da história passada sobre o relato foram também observados por Ribes e Rodríguez (2001, Experimento 1). Nesse estudo, quando instruções incorretas eram apresentadas após instruções corretas, não houve correspondência entre relato e instrução; quando ocorria o inverso, o relato foi controlado pela instrução.

As Figuras 1 e 2 também mostram que os relatos precisos foram mais freqüentes que os imprecisos, mesmo não havendo contingências programadas de reforço para a cor- 
respondência entre comportamento não verbal e comportamento verbal (ou punição para a não correspondência entre esses dois comportamentos). Considerações sobre o nível de precisão dos relatos foram feitas por Ribeiro (1989). Nesse estudo, quando os relatos de crianças não produziam qualquer tipo de feedback, foi observada correspondência entre o comportamento não verbal e os relatos, ou seja, os relatos foram precisos. $\mathrm{O}$ autor sugeriu que a maior ocorrência de relatos precisos que de imprecisos reflete os efeitos da história de reforçamento (para a precisão/correspondência) e punição (para a imprecisão/não correspondência) estabelecida pela comunidade verbal (ver também Amorim, 2001).

A punição dos relatos não foi acompanhada por mudanças nas respostas de escolha na maioria das condições experimentais (Figura 3). Em todas as condições da seqüência NÃO e na condição N da seqüência SIM, as porcentagens de escolhas corretas permaneceram semelhantes àquelas obtidas nas condições LB de cada seqüência, a despeito das manipulações do feedback para o relato. Tal resultado sugere independência funcional entre essas respostas, ou seja, que o relato e a escolha foram controlados por diferentes variáveis. Entretanto, esse efeito não foi observado nas condições $\mathrm{S}$ e $\mathrm{S} / \mathrm{N}$ para os participantes da seqüência SIM: nessas condições, a punição do relato "SIM" foi acompanhada por uma redução na acurácia das respostas de escolha. Evidências de independência e dependência funcional entre os desempenhos verbal e não verbal foram também descritas por Amorim (2001), Catania e cols. (1982), Cerutti (1991), Ribes e Rodríguez (2001) e Torgrud e Holborn (1990). Nesses estudos, a possibilidade de interação funcional entre esses desempenhos foi atribuída ao grau de controle discriminativo exercido pelas contingências programas. A questão da independência funcional ou, alternativamente, da insensibilidade de um desempenho às contingências programadas para outro desempenho será retomada na discussão geral.

\section{Experimento 2}

No experimento anterior, foram observados dois efeitos principais: (a) o feedback contingente às respostas de relato exerceu funções punitivas e (b) a influência da contingência de punição sobre as respostas de escolha dependeu da ordem de exposição às condições experimentais. No Experimento 2, o feedback foi programado contingente as respostas de escolha, com o objetivo de observar se essa manipulação exerceria efeitos punitivos sobre essas respostas e, também, sobre os relatos.

\section{Método}

\section{Participantes}

Quatro alunos do curso de graduação em Psicologia da Universidade Católica de Goiás (UCG), todos do sexo feminino e com idade variando de 18 a 21 anos, participaram desse estudo. Ao final do experimento, os alunos participaram do sorteio de uma quantia de $\mathrm{R} \$ 20,00$.

\section{Ambiente / Equipamento / Material}

As características do ambiente, do equipamento e dos materiais utilizados foram semelhantes às do Experimento 1.

\section{Procedimento}

Este experimento compreendeu duas etapas, assim como o Experimento 1: uma etapa preliminar e uma etapa experimental.

Etapa Preliminar. Essa etapa foi programada de modo semelhante aquele descrito no Experimento 1.

Etapa Experimental. Essa etapa difere daquela descrita no Experimento 1 no que se refere à programação da contingência de punição, ou seja, no presente experimento o feedback era contingente às respostas de escolha, nunca sendo produzido pelas respostas de relato.

Na condição de Linha de Base (LB), não havia apresentação do feedback.

Na condição CORRETA (C), 100\% das respostas de escolha corretas produziam o feedback "Incorreto. Você perdeu 1 ponto", sendo que nenhum feedback era apresentado caso o sujeito emitisse uma resposta de escolha incorreta.

Na condição CORRETA/INCORRETA(C/I), tanto as respostas de escolha corretas, quanto as incorretas, produziam o feedback $50 \%$ das vezes. Ou seja, metade das escolhas corretas e metade das escolhas incorretas tinham como conseqüência a apresentação do feedback.

Na condição INCORRETA (I), o feedback era apresentado $100 \%$ das vezes que o participante emitia uma resposta incorreta de escolha, sendo que as respostas de escolha corretas não produziam conseqüências programadas.

Após a última condição, o participante era exposto novamente à condição de Linha de Base (LB).

Os participantes passaram pelas condições em duas seqüências diferentes. Dois participantes foram expostos à seqüência LB - C - C/I - I -LB (seqüência CORRETA) e os outros dois participantes à seqüência $\mathrm{LB}-\mathrm{I}-\mathrm{C} / \mathrm{I}-\mathrm{C}-\mathrm{LB}$ (seqüência INCORRETA).

Relatos precisos resultavam no registro e acréscimo de um ponto ao total de pontos, enquanto relatos imprecisos produziam a diminuição de um ponto do total de pontos da sessão. Os pontos perdidos após as respostas de escolha eram subtraídos do total de pontos registrados para as respostas de relato. Assim como no Experimento 1, o participante não recebia fichas para participar do sorteio se o total de pontos estivesse negativo ao final da sessão. Além disso, nenhum contador era apresentado na tela, ou seja, os participantes não recebiam qualquer informação sobre o total de pontos ao longo da sessão.

A seguinte instrução foi utilizada antes da etapa experimental:

Este é um experimento sobre aprendizagem.

No monitor à sua frente, aparecerão 3 figuras-modelo na parte superior da tela. Em seguida, aparecerão 2 figuras de com- 
paração na parte inferior da tela. Sua tarefa consiste em escolher a figura de comparação idêntica a uma das figuras-modelo. Para tanto, você deve clicar com o mouse na figura de comparação escolhida. Dependendo da sua escolha, você receberá uma mensagem indicando que você perdeu 1 ponto.

Após cada escolha da figura de comparação, o computador lhe fará uma pergunta e apresentará algumas alternativas de resposta. Para responder, você deverá clicar com o mouse em uma das alternativas. Entretanto, você não receberá nenhuma mensagem indicando se sua resposta foi correta ou incorreta, nem se você ganhou ou perdeu 1 ponto. Além disso, o contador com o número total de pontos não será apresentado na tela.

Os pontos perdidos pela escolha da figura de comparação serão subtraídos dos pontos ganhos pela resposta à pergunta. Cada 5 pontos ganhos serão trocados por uma ficha que the permitirá participar do sorteio programado para o final do experimento.

Se, ao final da sessão, o contador com o total de pontos estiver negativo, você não receberá fichas para o sorteio. Quanto mais pontos você fizer, mais fichas receberá e, conseqüentemente, terá mais chances de ganhar o sorteio.

Clique OK quando estiver pronto para começar.

\section{Resultados e Discussão}

Nesse experimento, foram também analisadas as respostas de escolha e de relato, conforme feito no Experimento 1 . Entretanto, considerando que ofeedback seguiu as respostas de escolha, esta será inicialmente analisada.

\section{Respostas de escolha}

A Figura 4 apresenta a porcentagem de escolhas corretas dos participantes que foram expostos à seqüência CORRETA e dos participantes expostos à seqüência INCORRETA. O cálculo da porcentagem de escolhas corretas de cada participante foi semelhante àquele descrito na Figura 3.

Para os participantes de ambas as seqüências, a porcentagem de escolhas corretas manteve-se entre 70 e $90 \%$. A análise de variância mostrou não haver diferenças estatisticamente significativas entre as porcentagens de todas as condições da seqüência CORRETA, o mesmo ocorrendo para a seqüência INCORRETA. Esses resultados indicam que o feedback não exerceu funções punitivas sobre as respostas de escolha.

\section{Relatos "SIM" e "NÃO"}

A Figura 5 apresenta a porcentagem dos relatos precisos e imprecisos por oportunidade em cada condição, para os participantes da seqüência CORRETA. As porcentagens de cada participante foram calculadas de maneira idêntica àquela descrita na Figura 1. Os relatos "SIM" são apresentados nos gráficos superiores e os relatos "NÃO", nos gráficos inferiores, enquanto os relatos precisos são apresentados à esquerda e os imprecisos, à direita.

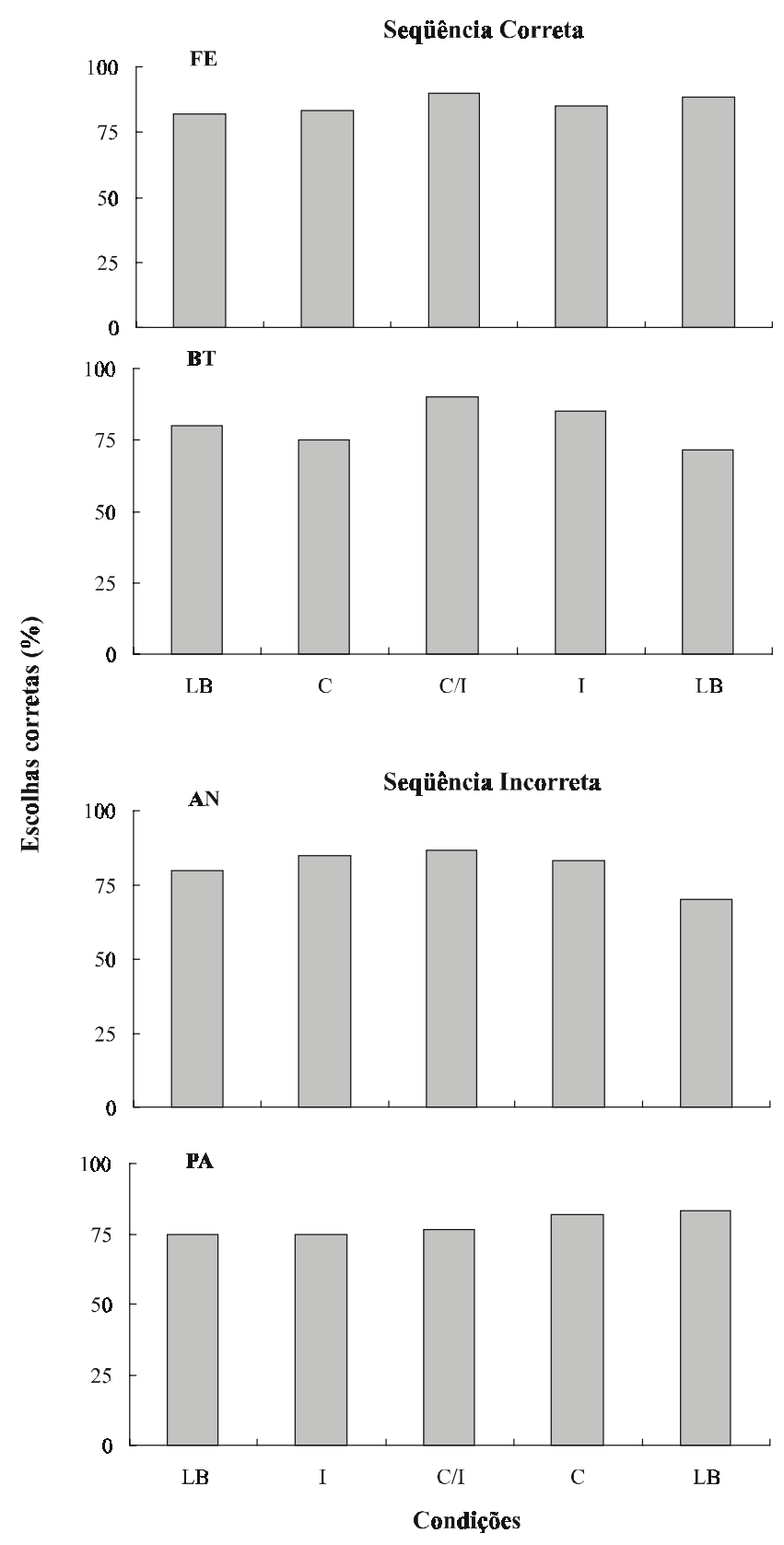

Figura 4. Porcentagem de escolhas corretas para os participantes da seqüência CORRETA (FE e BT) e para os participantes da seqüência INCORRETA (AN e PA), em cada condição experimental.

Analisando primeiramente as porcentagens dos relatos "SIM" e "NÃO", é possível observar que a porcentagem dos relatos "SIM" foi maior que a dos relatos "NÃO" em todas as condições experimentais, com exceção da condição $\mathrm{C}$ do participante BT, em que os relatos "NÃO" foram mais freqüentes. Além disso, as porcentagens de relatos "SIM" e relatos "NÃO" mantiveram-se relativamente inalteradas ao longo das condições.

A Figura 6 apresenta os resultados dos participantes da seqüência INCORRETA, com uma análise semelhante àquela apresentada na Figura 5. 


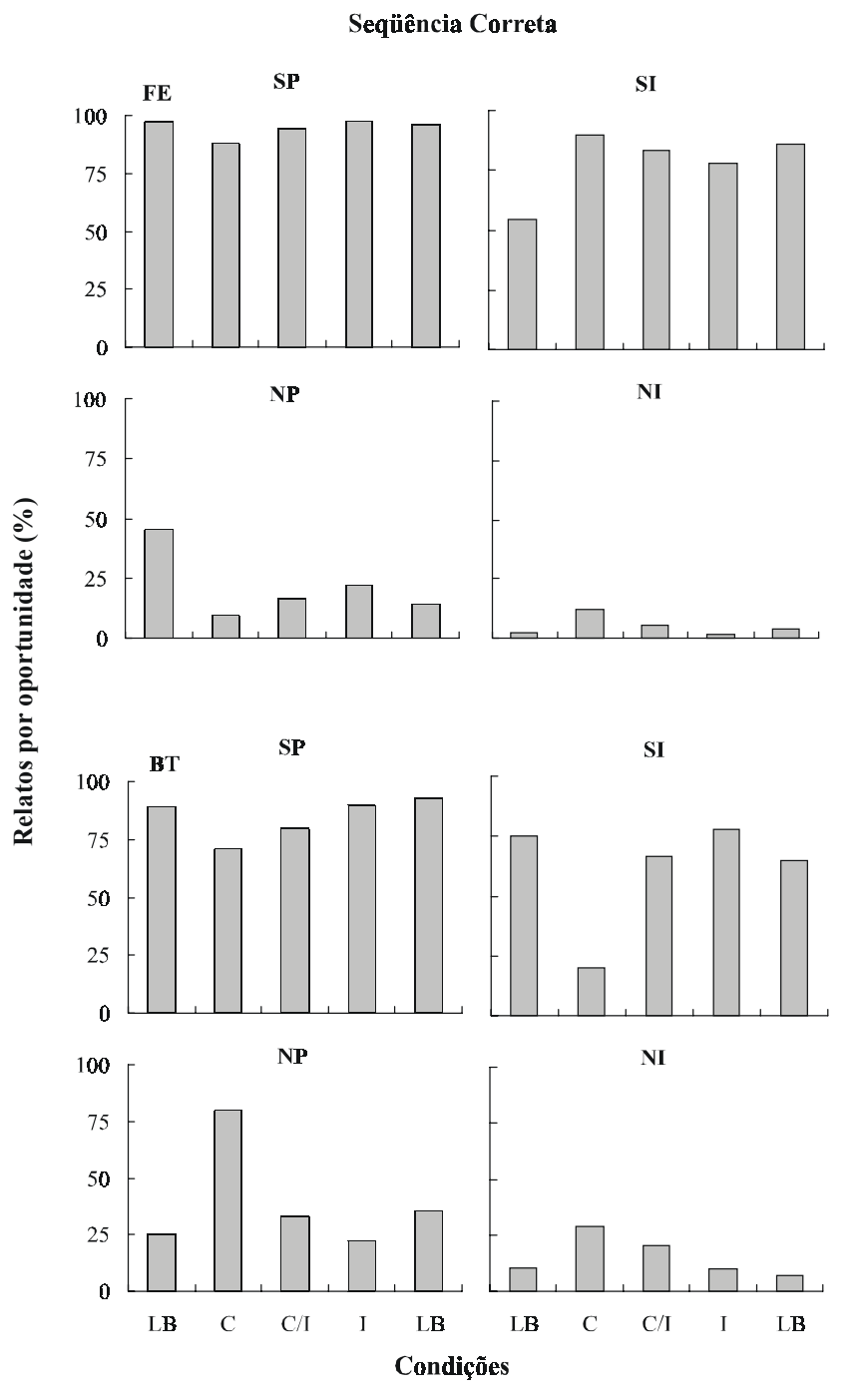

Figura 5. Porcentagem de relatos "SIM" precisos (SP) e imprecisos (SI) e relatos "NÃO" precisos (NP) e imprecisos (NI) por oportunidade para os participantes da seqüência CORRETA, em cada condição experimental.

A análise comparativa dos relatos "SIM" e "NÃO" mostra que a porcentagem dos relatos "SIM" foi superior à dos relatos "NÃO" na primeira condição LB. Nas condições seguintes, entretanto, não foram observados resultados sistemáticos: a porcentagem dos relatos "SIM" foi superior, semelhante ou inferior à dos relatos "NÃO".

\section{Relatos precisos e imprecisos}

A comparação dos relatos precisos e imprecisos, apresentada também na Figura 5, indica que a porcentagem dos relatos precisos foi maior do que a dos relatos imprecisos em todas as condições dos participantes da seqüência CORRETA, com exceção da condição $C$ do participante FE, em que os relatos imprecisos foram aproximadamente semelhantes aos precisos.

Conforme mostrado na Figura 6, a maior freqüência dos relatos precisos em relação aos imprecisos também ocorreu

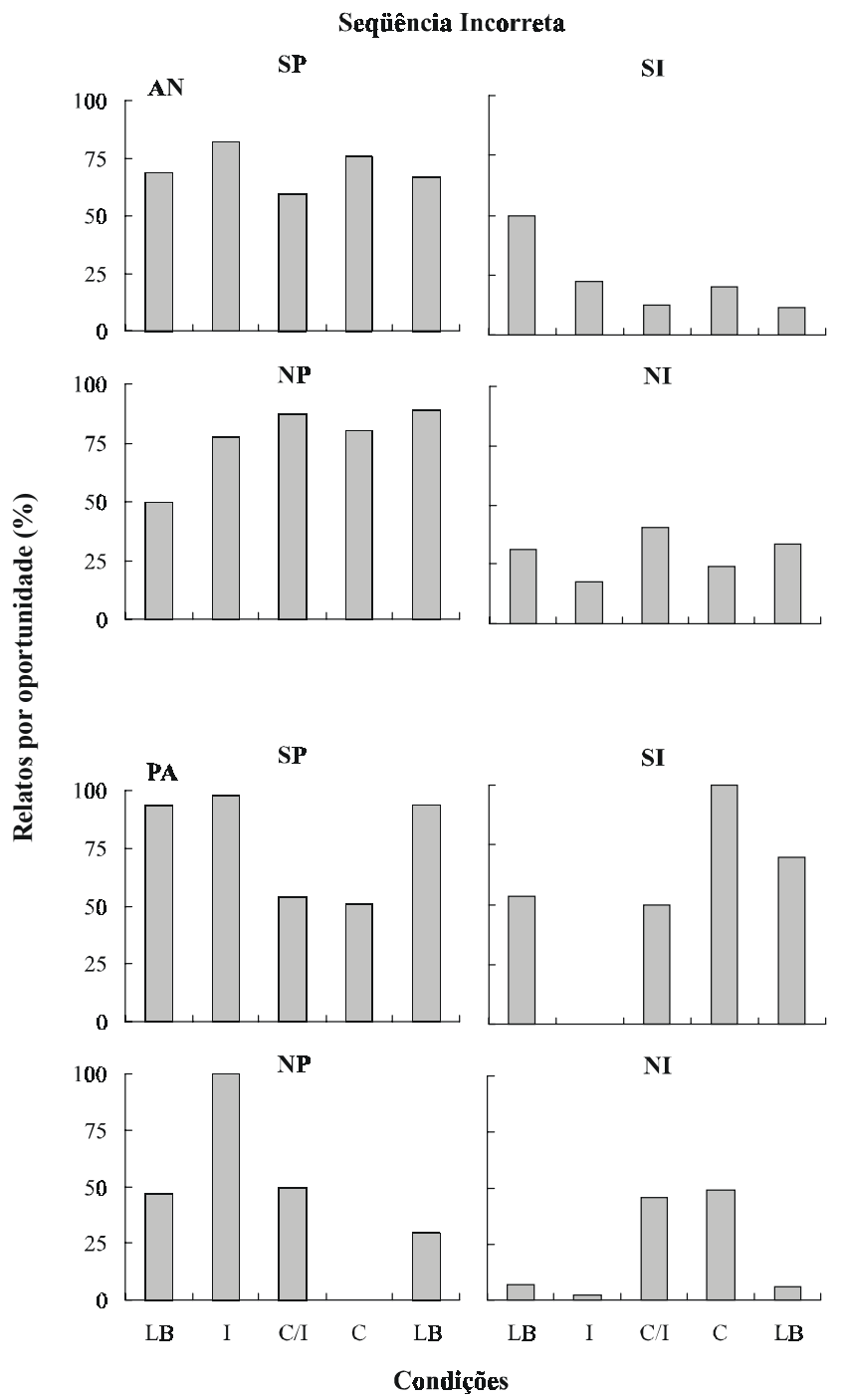

Figura 6. Porcentagem de relatos "SIM" precisos (SP) e imprecisos (SI) e relatos "NÃO" precisos (NP) e imprecisos (NI) por oportunidade para os participantes da seqüência INCORRETA, em cada condição experimental.

em todas as condições do participante $\mathrm{AN}$, exposto à seqüência INCORRETA. Para o participante PA, a freqüência dos relatos precisos foi superior a dos imprecisos nas condições LB e na condição I. Nas condições C/I e C, os relatos precisos apresentaram freqüências semelhantes ou inferiores aos relatos imprecisos, respectivamente.

Os resultados apresentados podem ser sintetizados em dois pontos principais. Em primeiro lugar, a contingência de punição programada não afetou as respostas de escolha, mas influenciou as respostas de relato. Esse resultado sugere independência funcional entre escolha e relato, conforme já observado no Experimento 1. Considerações sobre a insensibilidade da resposta de escolha à contingência de punição serão feitas na discussão geral.

Em segundo lugar, a análise dos relatos "SIM" e "NÃO" e dos relatos precisos e imprecisos sugere que o feedback afetou as respostas de relato. Para os participantes da seqüência CORRETA, o feedback produziu uma maior fre- 
qüência de relatos "SIM" (precisos e imprecisos) do que de relatos "NÃO" (precisos e imprecisos). Para os participantes da seqüência INCORRETA, entretanto, os relatos precisos ("SIM" e "NÃO") foram mais freqüentemente emitidos do que os relatos imprecisos ("SIM" e "NÃO"). Em suma, o feedback após escolhas corretas gerou imprecisão nos relatos (os indivíduos tenderam a relatar acertos), enquanto o feedback após escolhas incorretas produziu precisão nos relatos.

As características específicas de cada seqüência podem ser responsáveis pelos resultados descritos acima. Antes de cada condição, todos os participantes recebiam uma instrução indicando que sua tarefa consistia em escolher o estímulo de comparação idêntico ao estímulo-modelo. Na primeira condição LB, a elevada acurácia das respostas de escolha sugere controle antecedente pela instrução e pelos estímulos-modelo. Tais respostas presumivelmente estavam sendo reforçadas pela passagem para a próxima tentativa, pelo término da sessão e pelas fichas recebidas. Quando os participantes da seqüência CORRETA iniciavam a segunda condição (condição C), a apresentação do feedback era sempre incompatível com o controle antecedente exercido pela instrução e pelos estímulos-modelo: escolhas corretas recebiam o feedback "Incorreto" (e escolhas incorretas não produziam feedback). Em decorrência do contato com essa incompatibilidade, o feedback pode ter adquirido funções controladoras peculiares, isto é, a apresentação do feedback "Incorreto" passou a estabelecer ocasião para emissão de relatos "SIM", em vez de evocar relatos "NÃO". Esse controle "inverso", aliado a uma alta porcentagem de escolhas corretas, gerou uma maior predominância de relatos "SIM", sendo esse aumento observado não somente para os "SIM" precisos como também para os imprecisos. Isso provavelmente aconteceu porque a ausência de feedback após escolhas incorretas poderia estar funcionando como um feedback de acerto. Na condição I da seqüência INCORRETA, entretanto, não havia incompatibilidade entre instrução/estímulos-modelo e feedback: escolhas incorretas eram seguidas pelo feedback "Incorreto" e escolhas corretas não produziam feedback o que, novamente, seria equivalente ao feedback "Correto". A compatibilidade entre o feedback e os demais estímulos presentes na contingência fortaleceu a emissão de relatos precisos após escolhas corretas e incorretas.

Os resultados do Experimento 2, tanto aqueles relacionados às respostas de escolha quanto às respostas de relato, são consistentes com os dados apresentados por Ribes e Rodríguez (2001). Nesse estudo, manipulações no grau de acurácia das instruções não exerceram efeitos sobre as respostas de escolha, mas afetaram as respostas de relato. $\mathrm{Ou}$ seja, as escolhas foram corretas mesmo na presença de discrepância entre instrução e contingência. As respostas de relato, por outro lado, foram opostas às instruções inacuradas e correspondentes às instruções acuradas, um efeito que dependeu do grau de controle exercido pelas contingências programadas para a resposta de escolha. Similarmente, no presente estudo, as escolhas foram corretas a despeito da acurácia do feedback, enquanto os relatos não corresponde- ram ao feedback inacurado, mas corresponderam ao feedback acurado, sendo esse resultado afetado pela ordem de exposição às condições experimentais.

\section{Discussão Geral}

O presente estudo teve como objetivo investigar a influência de contingências de punição sobre os desempenhos verbal (relatos) e não verbal (escolhas). O feedback contingente às respostas de relato exerceu funções punitivas sobre tais respostas, mas não afetou as respostas de escolha (com exceção das condições $\mathrm{S}$ e $\mathrm{S} / \mathrm{N}$ da seqüência $\mathrm{SIM}$ ). O feedback contingente às respostas de escolha, por outro lado, não exerceu controle sobre estas respostas, mas influenciou as respostas de relato. Esses resultados sugerem que o desempenho verbal parece ser mais sensível a contingências de punição que o desempenho não verbal ou, alternativamente, que os desempenhos verbal e não verbal são funcionalmente independentes.

A independência funcional entre comportamento verbal e não verbal também foi observada em diversos outros estudos (e.g., Amorim, 2001; Catania \& cols., 1982; Cerutti, 1991; Ribes \& Rodríguez, 2001; Torgrud \& Holborn, 1990) e tem sido atribuída ao grau de controle discriminativo exercido pelas contingências. No estudo de Cerutti (1991), por exemplo, estudantes universitários foram instruídos a pressionar duas teclas para evitar a ocorrência de tons. Cada participante era designado para um de três grupos que se diferenciavam pela maneira como a ocorrência dos tons era programada, isto é, de acordo com um esquema misto tempo randômico-tempo randômico ( $m i x$ RT RT), misto tempo fixotempo fixo (mix FT FT) ou tempo fixo (FT). Os participantes também deveriam descrever seus desempenhos não verbais, sendo que tais descrições produziam pontos diferenciados. Para os participantes dos grupos mix RT RT e mix FT FT, as descrições ficaram sob controle de suas conseqüências e, mesmo não estando em acordo com as contingências não verbais, influenciaram as respostas de pressão às teclas. Para os participantes do grupo FT, as descrições também se mostraram sob controle de suas conseqüências; porém, tais descrições não afetaram as respostas de pressão às teclas, que foram adequadas ao esquema em vigor. De acordo com o autor, o esquema FT, ao contrário dos esquemas mistos, permitiu que a relação de independência entre as respostas de pressionar as teclas e a eliminação dos tons exercesse controle discriminativo, produzindo um desempenho não verbal em acordo com as contingências programadas e independente das descrições verbais. O autor concluiu, então, que o controle exercido por contingências verbais só é possível quando as contingências para o desempenho não verbal não exercem controle discriminativo. Resultados semelhantes foram obtidos por Torgrud e Holborn (1990).

No presente estudo, a independência funcional entre as respostas de escolha e de relato foi caracterizada pela insensibilidade das respostas de escolha às manipulações na contingência de punição. É possível que a contingência de punição estabelecida nos Experimentos 1 e 2 não tenha exerci- 
do influência sobre as escolhas devido à discriminabilidade das contingências programadas para estas respostas. No início de cada experimento, os participantes foram instruídos a escolher um estímulo de comparação idêntico a um dos estímulos-modelo (pareamento de identidade), sendo possível que esta instrução tenha potencializado as propriedades discriminativas desses estímulos (o que pode ser observado pelas porcentagens elevadas de acerto), tornando irrelevante o controle por estímulos adicionais (e.g., o feedback).

A questão da independência funcional entre os comportamentos verbal e não verbal também pode ser discutida à luz do conceito de bloqueio. De acordo com Catania (1999), "quando um estímulo deixa de se tornar um CS efetivo por ser apresentado juntamente com um outro estímulo que já é efetivo, dizemos que o estímulo com história anterior bloqueou o condicionamento para o novo estímulo" (p. 218). Em contextos operantes, um fenômeno similar ocorre quando estímulos com funções discriminativas bem estabelecidas impedem o desenvolvimento de controle por um outro estímulo, potencialmente discriminativo, também presente na situação (Danforth e cols., 1990; Otto e cols., 1999). Se o conceito de bloqueio operante for aplicado aos dados do presente estudo, é possível afirmar que as funções discriminativas exercidas pela instrução e pelos estímulosmodelo bloquearam o controle discriminativo pelos feedbacks e, conseqüentemente, as respostas de escolha não foram diferencialmente afetadas pelas contingências de punição.

Apesar da independência funcional entre escolha e relato ter sido observada na maioria das condições do Experimento $1 \mathrm{e}$ em todas as condições do Experimento 2, também foram obtidas evidências de interação funcional entre as contingências verbais e não verbais. Nas condições $\mathrm{Se} \mathrm{S} /$ $\mathrm{N}$ da seqüência SIM (Experimento 1), a punição dos relatos foi acompanhada por uma redução na porcentagem de escolhas corretas. As propriedades controladoras da instrução e dos estímulos-modelo nessas condições, embora devessem ser semelhantes àquelas observadas nas demais condições dos Experimentos 1 e 2 (uma vez que a contingência para a resposta de escolha era a mesma em ambos os experimentos), parecem ter sido afetadas pelo feedback para as respostas de relato, conforme sugere a redução na acurácia da resposta de escolha (Figura 3). Com base nos argumentos de Critchfield (1996), é possível sugerir que a história pré-experimental dos participantes tenha contribuído para esse efeito. Isto é, os participantes provavelmente tinham uma história de reforçamento para relatos de sucesso e uma história de punição para relatos de insucesso; a situação experimental, por outro lado, não somente punia os relatos de insucesso como também os relatos de sucesso ao longo das condições. Quando a condição $\mathrm{S}$, em que havia punição apenas para relatos de sucesso, ocorria logo após a condição LB (seqüência SIM), a incompatibilidade entre história pré-experimental e contingências programadas pode ter afetado a discriminabilidade dos estímulos-modelo e, conseqüentemente, reduzido a acurácia das escolhas. Essa sugestão é corroborada pelos dados observados quando a condição $\mathrm{S}$ ocorria após a condição $\mathrm{S} / \mathrm{N}$ (seqüência NÃO). Nesse caso, as respostas de escolha não foram afetadas pela contingência de punição, talvez porque a experiência anterior com a condição $\mathrm{S} / \mathrm{N}$, em que tanto os relatos de sucesso quanto os de insucesso eram punidos, pode ter minimizado a incompatibilidade entre história pré-experimental e contingências experimentais. Além disso, quando o participante não contatava a incompatibilidade logo no início do experimento (condição $\mathrm{N}$ da seqüência NÃO), a acurácia das respostas de escolha permaneceu inalterada em relação àquela observada na condição LB anterior. Essa sugestão, entretanto, requer investigações adicionais.

A dependência funcional entre os desempenhos verbais e não verbais também foi observada por Catania e cols. (1982). Nesse estudo, estudantes universitários deveriam pressionar botões de acordo com um esquema múltiplo razão randômica-intervalo randômico (mult RR 20 RI 10 s) e, a cada $3 \mathrm{~min}$, deveriam completar sentenças descrevendo seus desempenhos não verbais. O conteúdo das sentenças foi modelado, de modo a produzir sentenças que descreviam desempenhos consistentes ou não com as contingências em vigor. Os resultados demonstraram uma correspondência entre os comportamentos verbal e não verbal mesmo quando o comportamento verbal era contrário às contingências programadas para o comportamento não verbal.

De uma maneira geral, os resultados do presente estudo evidenciaram o caráter operante do auto-relato, demonstrando experimentalmente o controle de contingências de punição. Essa sensibilidade do auto-relato às contingências ambientais apóia as considerações de Shimoff (1986) de que tais comportamentos são multiplamente determinados e, assim, não mantêm, necessariamente, uma relação de correspondência com os eventos privados.

Esse resultado sugere que a utilização do auto-relato como um instrumento para acessar eventos privados deve ser vista com cautela. Uma vez que o auto-relato pode ser controlado por variáveis outras que não os eventos privados, e considerando que nem sempre é possível identificar suas variáveis de controle, o uso do auto-relato como instrumento fica comprometido e, conseqüentemente, os dados gerados são questionáveis. Entretanto, isso não justifica a exclusão dos auto-relatos como uma forma de observação, pois o problema não está nos auto-relatos em si. Qualquer tipo de instrumento pode produzir dados válidos do ponto de vista científico, desde que os fatores que influenciam tal instrumento sejam conhecidos e controlados (Critchfield, Tucker \& Vuchinich, 1998). Ou seja, para qualquer forma de observação, quer seja realizada por uma máquina, por um observador externo ou pelo próprio indivíduo, faz-se necessário identificar suas variáveis de controle para garantir a fidedignidade dos dados observados. O presente estudo, que investigou o auto-relato como uma variável dependente e cujos resultados demonstraram possíveis fontes de controle dos relatos, pode contribuir para uma maior fidedignidade dos dados obtidos por meio de auto-relatos. 


\section{Referências}

Amorim, C.F.R.B. (2001). O que se diz e o que se faz: um estudo sobre interações entre comportamento verbal e comportamento não verbal. Dissertação de mestrado não publicada, Pontifícia Universidade Católica de São Paulo.

Bentall, R.P., Lowe, C.F. \& Beasty, A. (1985). The role of verbal behavior in human learning: II. Developmental differences. Journal of the Experimental Analysis of Behavior, 43, 165-181.

Catania, A.C., Matthews, B.A. \& Shimoff, E. (1982). Instructed versus shaped human verbal behavior: Interactions with nonverbal responding. Journal of the Experimental Analysis of Behavior, 38, 233-248.

Catania, A.C. (1999). Aprendizagem - Comportamento, Linguagem e Cognição. (A. Schmidt, D.G. de Souza, F.C. Capovilla, J.C.C. de Rose, M.J.D. dos Reis, A.A. da Costa, L.M.C.M. Machado e A. Gadotti, Trads.) Porto Alegre: Artmed. (Trabalho original publicado em 1979).

Cerutti, D.T. (1991). Discriminative versus reinforcing properties of schedules as determinants of schedule insensitivity in humans. The Psychological Record, 41, 51-67.

Critchfield, T.S. (1993). Signal-detection properties of verbal selfreports. Journal of the Experimental Analysis of Behavior, 60, 495-514.

Critchfield, T.S. (1996). Differential latency and selective nondisclosure in verbal self-reports. The Analysis of Verbal Behavior, 13, 49-63.

Critchfield, T.S. \& Perone, M. (1990). Verbal self-reports of delayed matching to sample by humans. Journal of the Experimental Analysis of Behavior, 53, 321-344.

Critchfield, T.S. \& Perone, M. (1993). Verbal self-reports about delayed matching to sample: Effects of the number of elements in a compound sample stimulus. Journal of the Experimental Analysis of Behavior, 59, 193-214.

Critchfield, T.S., Tucker, J.A. \& Vuchinich, R.E. (1998). Self-reports methods. Em K.A. Lattal \& M. Perone (Orgs.), Handbook of Research Methods in Human Operant Behavior (pp. 435-470). Plenum Press, N.Y.

Danforth, J.S., Chase, P.N., Dolan, M. \& Joyce, J.H. (1990). The stablishment of stimulus control by instructions and by differential reinforcement. Journal of the Experimental Analysis of Behavior, 54, 97-112.

Dixon, M.R. \& Hayes, L.J. (1998). Effects of differing instructional histories on the resurgence of rule-following. The Psychological Record, 48, 275-292.

Galizio, M. (1979). Contingency-shaped and rule-governed behavior: instructional control of human loss avoidance. Journal of the Experimental Analysis of Behavior, 31, 53-70.

Hayes, S.C. (1986). The case of the silent dog - Verbal reports and the analysis of rules: A review of Ericsson and Simon's protocols analysis: Verbal reports as data. Journal of the Experimental Analysis of Behavior, 45, 351-363.

Kaufman, A., Baron, A. \& Kopp, R.E. (1966). Some effects of instructions on human operant behavior. Psychonomic Monograph Supplements, 1, 243-250.

LeFrancois, J.R., Chase, P.N. \& Joyce, J.H. (1988). The effects of a variety of instructions on human fixed-interval performance.
Journal of the Experimental Analysis of Behavior, 49, 383393.

Ono, K. (1994). Verbal control of superstitious behavior: Superstitious as false rules. Em S.C.Hayes, L.J. Hayes, M. Sato \& K. Ono (Orgs.), Behavior Analysis of Language and Cognition. (pp. 181-196). Reno (NV): Context Press.

Otto, T.L., Torgrud, L.J. \& Holborn, S.W. (1999). An operant blocking interpretation of instructed insensitivity to schedule contingencies. The Psychological Record, 49, 663-684.

Perone, M. (1988). Laboratory lore and research practices in the experimental analysis of human behavior: Use and abuse of subjects' verbal reports. The Behavior Analyst, 11, 71-75.

Raia, C.P., Shillingford, S.W., Miller Jr. H.L. \& Baier, P.S. (2000). Interaction of procedural factors in human performance on yoked schedules. Journal of the Experimental Analysis of Behavior, 74, 265-281.

Ribeiro, A.F. (1989). Correspondence in children's self-report: Tacting and manding aspects. Journal of the Experimental Analysis of Behavior, 51, 361-367.

Ribes, E., \& Rodriguez, M.E. (2001). Correspondence between instructions, performance, and self-descriptions in a conditional discrimination task: the effects of feedback and type of matching response. The Psychological Record, 51, 309-333.

Rosenfarb, I.S., Newland, C.M., Brannon, S.E. \& Howey, D.S. (1992). Effects of self-generated rules on the development of schedule-controlled behavior. Journal of the Experimental Analysis of Behavior, 58, 107-121.

Shimoff, E. (1986). Post-session verbal reports and the experimental analysis of behavior. The Analysis of Verbal Behavior, 4, $19-22$.

Simonassi, L.E., Oliveira, C.I. \& Gosch, C.S. (1997). Exposição a contingências, conteúdo de instrução e formulação de regras. Psicologia: Teoria e Pesquisa, 13, 189-195.

Smith, R., Michael, J. \& Sundberg, M.L. (1996). Automatic reinforcement and automatic punishment in infant vocal behavior. The Analysis of Verbal Behavior, 13, 39-48.

Skinner, B.F. (1957). O Comportamento Verbal. São Paulo: Cultrix. Torgrud, L.J. \& Holborn, S.W. (1990). The effects of verbal performance descriptions on nonverbal operant responding. Journal of the Experimental Analysis of Behavior, 54, 273-291. 